\title{
Structural dynamic response of underground structure with vertical ground motion input
}

\author{
Tong Liu ${ }^{1}$, Fuwang $\mathrm{Xu}^{2}$, Qinghe Wang ${ }^{3, *}$, Huaiyu $\mathrm{Xu}^{3}$ \\ ${ }^{1}$ School of Management, Shenyang Jianzhu University, Shenyang 110168, China. \\ ${ }^{2}$ China Communications Tunnel Engineering Company Limited, Fujian 353100, China. \\ ${ }^{3}$ School of Civil Engineering, Shenyang Jianzhu University, Shenyang 110168, China.
}

\begin{abstract}
Since many cases of structural damage in past earthquakes have been attributed to strong vertical ground motion, our understanding of vertical seismic load effects and their influence on seismic performance of subway station structure is limited. In this study, the Daikai subway station is taken as a typical example. A two-dimensional finite element model of both soil and structure was established using finite element software ABAQUS. Two input approaches of ground motion are considered, including the horizontal component alone and the vertical and horizontal motions simultaneously. Four groups of ground motion records are selected according to the site type of this station and scaled to the strong intensity which can make the station damage. Results show that the vertical seismic load increases the axial force of the column component apparently, while horizontal seismic load has little effect on axial compression ratio.
\end{abstract}

\section{Introduction}

Since the Kobe earthquake at Japan in 1995, enough attention has been paid to the seismic performance of underground structure. Researchers have carried out a series of studies on the seismic performance of various underground subway station structures ${ }^{[1-3]}$. For example, Huo et al. ${ }^{[1]}$ conduct dynamic time-history analysis on the Daikai subway station using the finite element software ABAQUS, and systematically analyzed the force transfer mechanism and failure mechanism of both soil and structure. Zhuang et al. ${ }^{[2]}$ conduct numerical simulation analysis on the nonlinear seismic response of the Dakai subway station using the finite element software ABAQUS. However, these research mainly focus on structural dynamic characteristic under horizontal or horizontal and vertical ground motion input, while the research on the comparison between these two cases is limited.

Besides, studies have shown that the damage of underground structure under seismic load is related to the large vertical ground motion, and the vertical ground motion component in some earthquake areas is greater than the horizontal ground motion component ${ }^{[4-6]}$. For example, the collapse of the middle layer of multi-storey building structure and the destruction of the central column of underground structure in the Kobe earthquake in 1995 are related to the vertical ground motion. Therefore, the influence of vertical ground motion on structural damage cannot be ignored.
In this paper, the Daikai subway station is taken as a typical example and the numerical model is developed using the finite element software ABAQUS. Four groups of ground motion records are selected according to the type of site, and the dynamic response characteristics of the structure under different ground motion input conditions are investigated through the ground motion amplitude modulation method of incremental dynamic analysis.

\section{Numerical modeling}

Based on the general profile of Daikai station ${ }^{[1]}$, the cross section with $17 \mathrm{~m}$ wide and $7.17 \mathrm{~m}$ high, as shown in Figure 1 , is taken into consideration. The cross section of central column is $0.4 \mathrm{~m}$ by $1.0 \mathrm{~m}$, with space of $3.5 \mathrm{~m}$ in longitudinal direction. The soil condition is shown in Table 1 .

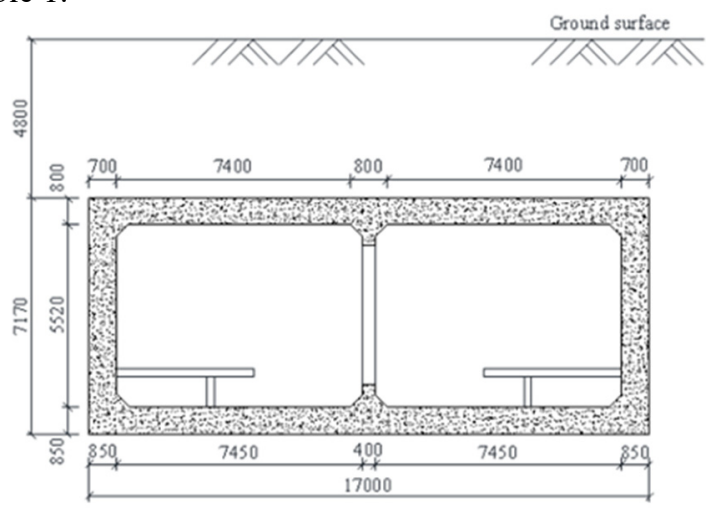

Figure 1. Cross section of Daikai station (unit: $\mathrm{mm})^{[1]}$.

\footnotetext{
${ }^{*}$ Corresponding author: wangqinghe@sjzu.edu.cn
} 
A detailed two-dimensional model of Daikai station and the layered soil is established using finite element software package ABAQUS ${ }^{[7]}$. As illustrated in Figure 2, the numerical model is $1000 \mathrm{~m}$ long and $58 \mathrm{~m}$ high, among which the structural members are simulated through beam element(B21), and the Young's modulus and unit weight of concrete are $24 \mathrm{GPa}$ and $25 \mathrm{kN} / \mathrm{m}^{3}$, respectively.

The soil is simulated using four-node plain strain element (CPE4R) as well as the infinite element (CINPE4). For the detail statistics of numerical model and its verification, please refer to Liu et al. ${ }^{[8]}$.

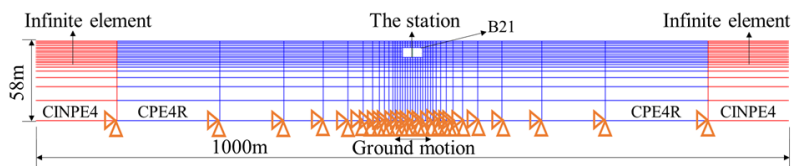

Figure 2. Numerical modeling of Daikai station.

\section{Incremental dynamic analysis}

To investigate seismic performance of subway station under vertical motion, four groups ground motion records are selected herein based on the soil condition, as illustrated in Table 2, during which Mi means horizontal ground motion and Vi means vertical ground motion. The simulated cases include horizontal motion input $(\mathrm{H})$, horizontal and vertical motions input $(\mathrm{H} \& \mathrm{~V})$. The horizontal motions are scaled with peak velocity as 3, 5, $10,20,30,40,50,60,70,80 \mathrm{~cm} / \mathrm{s}$, and the vertical motion is 0.67 times of horizontal intensity. Besides, peak acceleration at the base of structure (PBA) is selected as intensity measure and maximum inter-story drift angle $\left(\theta_{\max }\right)$ and axial compression ratio $(\alpha)$ are chosen as damage measure of incremental dynamic analysis (IDA). Then, with nonlinear dynamic time-history analysis, the seismic response under increasing seismic intensity can be obtained.

Table1. Soil parameter of Daikai station.

\begin{tabular}{|c|c|c|c|c|c|c|c|}
\hline Sequence & Name & Depth $(\mathrm{m})$ & $\begin{array}{c}\text { Unit Weight } \\
\left(\mathrm{kN} / \mathrm{m}^{3}\right)\end{array}$ & $\begin{array}{c}\text { Cohesion } \\
(\mathrm{kPa})\end{array}$ & $\begin{array}{c}\text { Friction Angle } \\
\left({ }^{\circ}\right)\end{array}$ & $\begin{array}{c}\text { Poisson's } \\
\text { Ratio }\end{array}$ & $\begin{array}{c}\text { Elastic } \\
\text { Modulus } \\
(\mathrm{MPa})\end{array}$ \\
\hline 1 & Fill & $0-1$ & 19 & 20 & 15 & 0.33 & 101.308 \\
\hline 2 & Holocene clay & $1-2$ & 19 & 30 & 20 & 0.32 & 101.308 \\
\hline 3 & Holocene sand & $2-4.8$ & 19 & 1 & 40 & 0.32 & 147.840 \\
\hline 4 & Pleistocene sand & $4.8-8$ & 19 & 1 & 40 & 0.40 & 195.972 \\
\hline 5 & Pleistocene clay & $8-17$ & 19 & 30 & 20 & 0.30 & 290.342 \\
\hline 6 & Pleistocene gravel & $17-$ & 20 & 1 & 40 & 0.26 & 560.045 \\
\hline
\end{tabular}

Table2. Ground motion records.

\begin{tabular}{|c|c|c|c|c|c|}
\hline No. & Event & Station & Component & PGA(g) & PGV(cm/s) \\
\hline M1 & Chi-Chi, Taiwan, 1999 & CHY101 & CHY101-E & 0.353 & 70.64 \\
\hline M2 & Chi-Chi, Taiwan, 1999 & CHY101 & CHY101-N & 0.439 & 115.0 \\
\hline V1 & Chi-Chi, Taiwan, 1999 & CHY101 & CHY101-V & 0.166 & 27.10 \\
\hline M3 & Chi-Chi, Taiwan, 1999 & TCU050 & TCU050-E & 0.147 & 36.91 \\
\hline M4 & Chi-Chi, Taiwan, 1999 & TCU050 & TCU050-N & 0.130 & 42.36 \\
\hline V2 & Chi-Chi, Taiwan, 1999 & TCU050 & TCU050-V & 0.088 & 42.16 \\
\hline
\end{tabular}




\begin{tabular}{|c|c|c|c|c|c|}
\hline M5 & Chi-Chi, Taiwan, 1999 & TCU065 & TCU065-E & 0.79 & 125.35 \\
\hline M6 & Chi-Chi, Taiwan, 1999 & TCU065 & TCU065-N & 0.575 & 92.13 \\
\hline V3 & Chi-Chi, Taiwan, 1999 & TCU065 & TCU065-V & 0.263 & 69.41 \\
\hline M7 & Chi-Chi, Taiwan, 1999 & CHY025 & CHY025-E & 0.162 & 50.92 \\
\hline M8 & Chi-Chi, Taiwan, 1999 & CHY025 & CHY025-N & 0.155 & 32.88 \\
\hline V4 & Chi-Chi, Taiwan, 1999 & CHY025 & CHY025-V & 0.173 & 38.03 \\
\hline
\end{tabular}

\section{Results}

As shown in Figure 3, structural dynamic response under two ground motion input approaches are compared. At the initial stage of IDA curve development, the structure is in the elastic stage, and the curves almost coincide, which means that the two input approaches have little influence on structural dynamic response. However, when it comes to the elastic-plastic stage, the structural dynamic responses obtained under the two input methods are

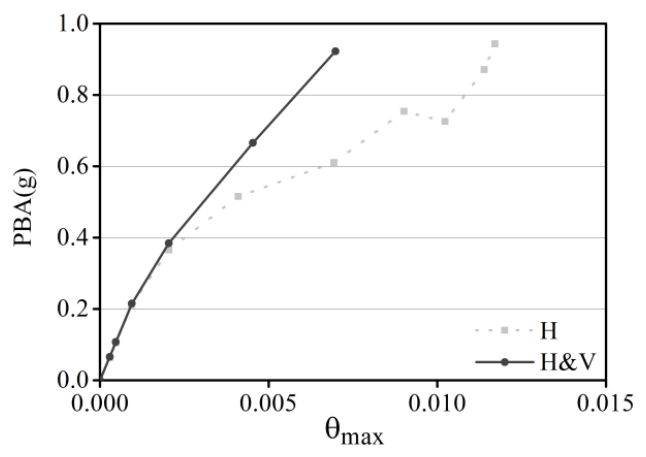

(a) CHY101

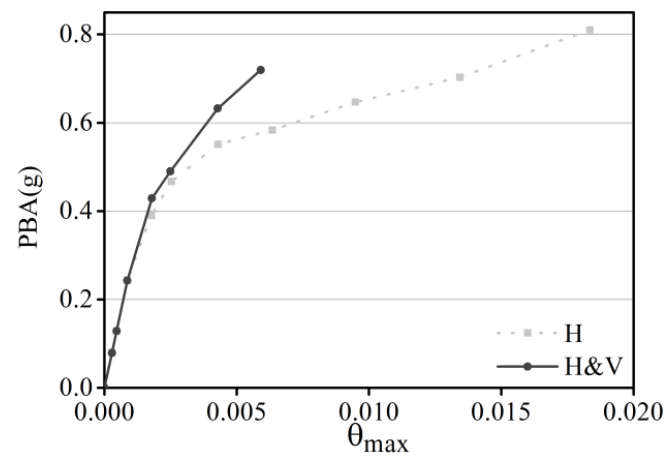

(b) TCU050 obviously different, during which the data of $\theta_{\max }$ with $\mathrm{H} \& \mathrm{~V}$ input is less than that of the $\mathrm{H}$ input.

As illustrated in Figure 4, the axial compression ratio of central column changes slightly with the increase of ground motion intensity under $\mathrm{H}$ input only, which varies between 0.3 and 0.5 . However, when the structure under horizontal and vertical seismic load simultaneously, the axial compression ratio of central column increases obviously with the increase of the ground motion intensity. Moreover, the axial compression ratio of central column under $\mathrm{H} \& \mathrm{~V}$ input is greater than that of $\mathrm{H}$ input, which varies from $8 \%$ to $93 \%$ range.

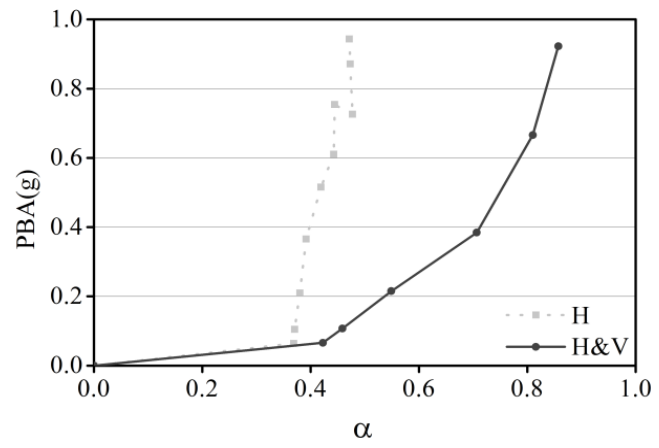

(a) CHY101

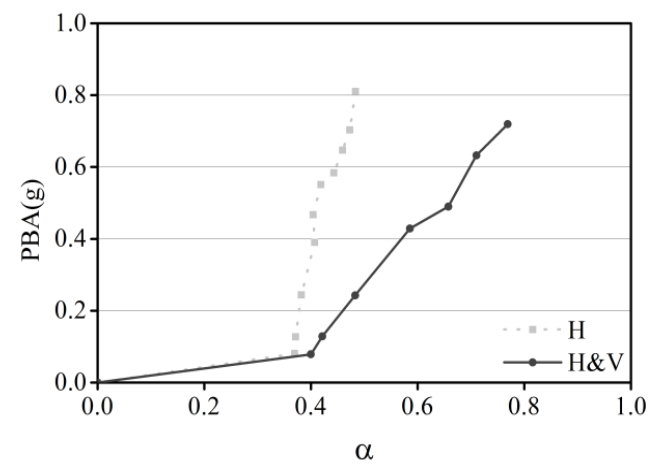

(b) TCU050 


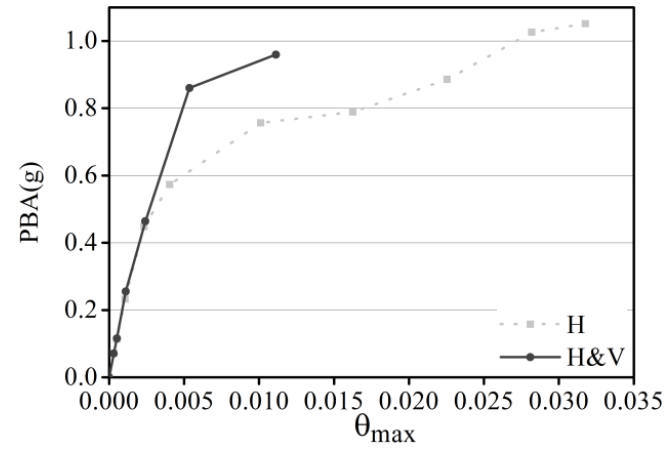

(c) TCU065

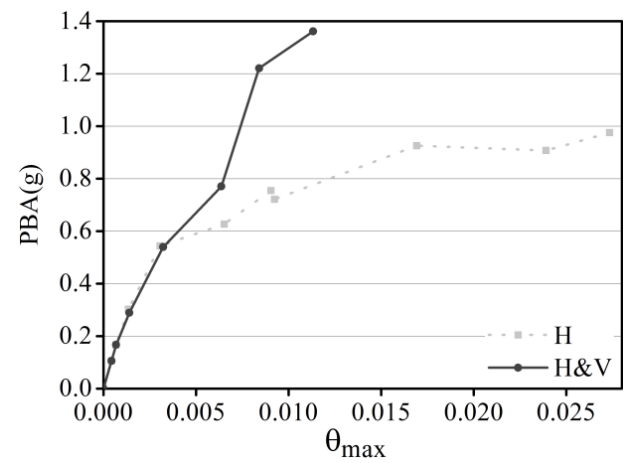

(d) $\mathrm{CHY} 025$

Figure 3. IDA curves with $\theta_{\max }$ as DM.

From the IDA results with $\theta_{\max }$ and axial compression ratio as DM respectively, it can be summarized that the lateral deformation of structure is greatly influenced by the horizontal ground motion, and the axial compression ratio of the central column is mainly controlled by the vertical ground motion, and the horizontal ground motion has little effect on the axial compression ratio. Therefore, the axial compression ratio should be considered as an important index during the design of structural vertical member.

\section{Conclusion}

In this study, the Daikai subway station is taken as a typical example and its seismic performance under vertical ground motion is investigated through incremental dynamic analysis. The conclusions are as follows.

(1) Structural lateral displacement is mainly influenced by horizontal ground motion.

(2) The axial compression ratio of central column is controlled by vertical ground motion, but not the horizontal ground motion.

(3) It is suggested herein that the axial compression ratio should be taken as an important index during vertical member design.

\section{Acknowledgements}

The research work in this paper was supported by LiaoNing Revitalization Talents Program, China (XLYC1902027), by Doctoral Scientific Research

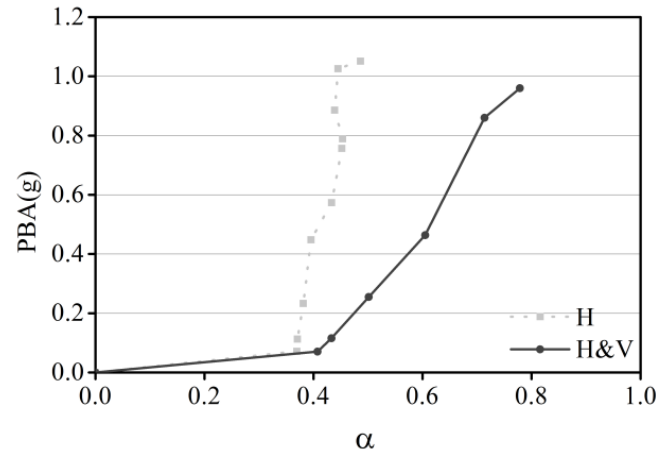

(c) TCU065

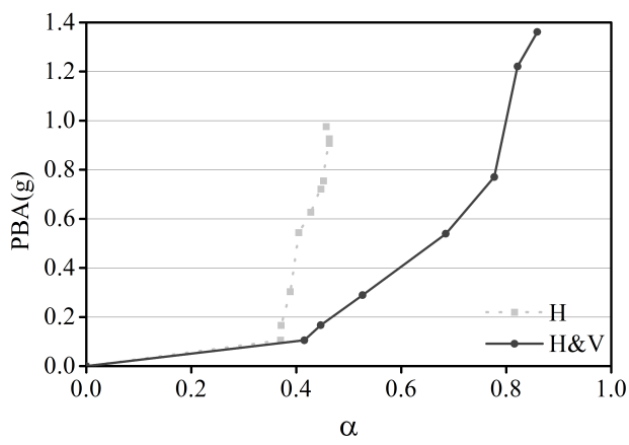

(d) $\mathrm{CHY} 025$

Figure 4. IDA curves with $\alpha$ as DM.

Foundation, China (2019-BS-193), by Science and Technology Project of MHRUD, China ( 2019 - K - 054 ), by Shenyang Science and Technology Project, China (RC200143) and Tianjin Science and Technology Project, China (18ZXGDGX00030).

\section{References}

1. Huo H, Bobet A, Fernández G, et al. Load Transfer Mechanisms Between Underground Structure and Surrounding Ground: Evaluation of the Failure of the Daikai Station[J]. Journal of Geotechnical \& Geoenvironmental Engineering, 2005, 131(12): 1522-1533.

2. Zhuang H Y, Chen S G, Chen G X. Numerical Simulation and Analysis of Earthquake Damage of Daikai Metro Station Caused by Kobe Earthquke[J]. Rock and Soil Mechanics, 2008, 29(1): 245-250 (in Chinese).

3. Du X L, Ma C, Lu D C, et al. Collapse Simulation and Failure Mechanism Analysis of the Dakai Subway Station Under Seismic Loads[J]. China Civil Engineering Journal, 2017, 50(1): 53-62+69 (in Chinese).

4. Tao L J, Li J D, Wu B L, et al. Influence of the Vertical Seismic Wave on the Seismic Response of an Largespan High-section Y-shaped Column Subway Station[J]. China Earthquake Engineering Journal, 2015, 37(3): 648-654 (in Chinese).

5. Guo S B, Zhao Y, Zhao Y T, et al. Dynamic Analysis of under ground Structures under the Vertical and 
Horizontal Seismic Load[J]. Underground Space, 2002, 22(4): 314-319 (in Chinese).

6. Chen C S, Qi C Z, Qian Q H, et al. Dynamic response of the Roof Slab of a Shallowly Buried Underground Structure Under Vertical Seismic Excitation[J]. World Earthquake Engineering, 2010, 26(4): 86-92 (in Chinese).

7. ABAQUS, Users Manual V. 6.10-1. 2010. Dassault Systemes Simulia Corp., Providence, RI.

8. Liu T, Chen Z, Yuan Y, et al. Fragility Analysis of a Subway Station Structure by Incremental Dynamic Analysis[J]. Advances in Structural Engineering, 2017, 20(7): 1111-1124. 